Published in final edited form as:

J Rheumatol. 2012 February ; 39(2): 337-344. doi:10.3899/jrheum.110040.

\title{
Racial Differences in Knee Osteoarthritis Pain: Potential Contribution of Occupational and Household Tasks
}

\author{
KELLI D. ALLEN, PhD [Associate Research Professor], \\ Health Services Research and Development Service, Durham Veterans Affairs Medical Center, \\ Durham, North Carolina; Department of Medicine, Division of General Internal Medicine, Duke \\ University Medical Center, Durham, North Carolina
}

JIU-CHIUAN CHEN, MD, ScD [Associate Professor],

Department of Preventive Medicine, University of Southern California Keck School of Medicine, Los Angeles, California

\section{LEIGH F. CALLAHAN, PhD [Associate Professor],}

Departments of Medicine, Orthopaedics, Social Medicine, University of Chapel Hill, Thurston Arthritis Research Center, Chapel Hill, North Carolina

YVONNE M. GOLIGHTLY, PT, PhD [Postdoctoral Fellow],

Thurston Arthritis Research Center, University of Chapel Hill, Chapel Hill, North Carolina

CHARLES G. HELMICK, MD [Medical Epidemiologist],

Centers for Disease Control and Prevention, Atlanta, Georgia, USA

JORDAN B. RENNER, MD [Professor],

Department of Radiology, University of Chapel Hill, Thurston Arthritis Research Center, Chapel Hill, North Carolina

TODD A. SCHWARTZ, DrPH [Research Assistant Professor], and

Department of Biostatistics, University of Chapel Hill, Chapel Hill, North Carolina

JOANNE M. JORDAN, MD, MPH [Professor]

Departments of Medicine and Orthopaedics, University of Chapel Hill, Thurston Arthritis Research Center, Chapel Hill, North Carolina

\begin{abstract}
Objective-We examined whether occupational and household tasks contributed to differences in pain between African Americans and whites with radiographic knee osteoarthritis (OA).

Methods-Participants from the Johnston County Osteoarthritis Project self-reported the frequency (often/always vs never/seldom/sometimes) of performing 9 occupational tasks involving lower extremity joint loading at their longest job $(\mathrm{N}=868)$ and current job $(\mathrm{N}=273)$, as
\end{abstract}

Copyright () 2011. All rights reserved.

Address correspondence to K.D. Allen, HSR\&D (152), VA Medical Center, 508 Fulton Street, Durham, NC 27705, USA. kelli.allen@duke.edu.

The findings and conclusions in this report are those of the authors and do not necessarily represent the official position of the Centers for Disease Control and Prevention or the Department of Veterans Affairs. 
well as 8 household tasks ever performed $(\mathrm{N}=811)$ and currently being performed $(\mathrm{N}=767)$. The associations of the numbers of occupational or household tasks with the Western Ontario and McMaster Universities Osteoarthritis Index (WOMAC) pain subscale were first examined in simple linear regression models. If significantly associated with greater pain, each of these was included in adjusted linear regression models to examine whether the association of race with pain remained statistically significant.

Results-African Americans reported significantly greater WOMAC pain scores than whites. Exposures to more occupational tasks at the longest job and the current job were associated with greater WOMAC pain scores $(\mathrm{p}<0.01)$. The association of race with greater pain scores remained statistically significant when controlling for occupational tasks at the longest job, but was reduced by $26 \%$ and no longer significant when controlling for the number of current occupational tasks. Exposures to an increasing number of household tasks were associated with lower pain scores and were not further analyzed.

Conclusion-Current performance of physically demanding occupational tasks contributed to racial differences in pain severity among individuals with knee OA. Better workplace policies to accommodate OA-related limitations may help to reduce racial differences in pain.

\section{Keywords}

OSTEOARTHRITIS; OCCUPATIONS; KNEE

Studies have shown that African Americans with osteoarthritis (OA) report greater pain severity than whites ${ }^{1,2,3,4,5}$. Recent studies suggest some potential explanatory factors may include body mass index (BMI) and psychological variables (depressive symptoms, emotion-focused coping, arthritis self-efficacy $)^{2,5}$. However, 1 potential explanatory factor not previously addressed is exposure to occupational or household tasks that involve substantial joint loading (i.e., kneeling, squatting, lifting heavy objects). This is important to examine for 2 reasons. First, prior studies indicated that occupational joint loading is associated with risk for developing $\mathrm{OA}^{6,7,8}$, and it is possible that this factor also contributes to pain severity. While less is known about the contribution of household activities to OA, it is also possible that physically demanding occupational tasks are associated with worse OA pain. Second, there are important historic and current racialdifferences in occupations. African Americans and other racial and ethnic minority groups tend to have more physically demanding occupations than whites ${ }^{9}$, and some research suggests they also experience greater levels of occupational musculoskeletal injuries ${ }^{10}$. These racial differences in occupational exposures could lead to subsequent disparities in the development of OA. However, it is not known whether occupational or household tasks may contribute independently to racial differences in pain severity among individuals with OA.

Our primary objective was to examine whether the number of physically demanding occupational or household tasks contributed to differences in pain severity between African Americans and whites with radiographic knee OA in the Johnston County Osteoarthritis Project (JoCo OA). When there was an association, we also examined the contribution of specific tasks. Because participants in JoCo OA reported both current and previous 
occupational and household tasks, we were able to separately examine the potential contribution of each of these 4 types of exposures to racial differences in pain severity.

\section{MATERIALS AND METHODS}

\section{Subjects}

This cross-sectional sample consisted of individuals enrolled in JoCo OA, an ongoing population-based study of the occurrence of hip and knee OA in a rural biracial population of the state of North Carolina (NC). Details of this study have been reported ${ }^{11}$. Briefly, the study involved civilian, noninstitutionalized adults aged 45 years and older who resided in 6 townships in Johnston County, NC. At baseline (1990-97), participants were recruited with oversampling of African Americans. The present analysis used data collected from individuals who had participated in either the first followup of the study $(n=1733)$ in 1999-2004, or those newly enrolled $(n=1015)$ in 2003-4. The new enrollment aimed to enrich the sample for African Americans and younger individuals; thus these participants were younger (mean age 59.3 vs 65.8 yrs, respectively) and more likely to be African American (40\% vs 28\%), compared to participants of the first followup study.

Participants underwent posterior-anterior (PA) radiography of both knees with weightbearing using a Synaflex positioning device. All radiographs were read for KellgrenLawrence (K-L) score by a single bone and joint radiologist (JBR) without regard to participant's clinical status or occupational tasks. Interrater and intrarater reliability of the radiologist were high (weighted $\kappa=0.9$ ), as reported ${ }^{11}$. These analyses were restricted to participants with radiographic knee $\mathrm{OA}$, defined as K-L grade $\geq 2$.

\section{Outcome measure: lower extremity pain severity}

Lower extremity pain severity was assessed using the Western Ontario and McMaster Universities Osteoarthritis Index (WOMAC) pain subscale ${ }^{12,13}$. This measure includes 5 items (pain with walking, stair climbing, in bed at night, sitting or lying down, and standing) rated on a scale of none $=0$ to $4=$ extreme, with a possible range of $0-20$.

\section{Occupational and household tasks and related subsamples. Occupational tasks at longest job ever held - Subsample A}

JoCo participants were asked, "Have you ever held a job outside the home or farm for pay for more than 1 year?". Those who responded "No," or that they did only homemaking and/or farming (at the home), were excluded from analyses of occupational tasks at the longest job ever held. Those who responded "Yes" comprised Subsample A and were asked to identify the job they held the longest and then asked whether they performed each of the following 9 tasks at that job: walking, lifting/carrying/moving objects weighing $>10$ pounds, standing, bending/twisting/reaching, squatting, climbing stairs, crawling on knees, crouching or kneeling, and doing heavy work while standing. The frequency of performing each of these 9 physical tasks was rated on a 5-level scale, with participants classified as being exposed to the indicated task if they performed it often/always (vs never/seldom/ sometimes). To assess the potential effect jointly contributed by these occupational tasks, we 
computed the total number of these tasks to which each participant reported exposure at their longest job (ranging from 0 to 9 ).

\section{Occupational tasks at current job - Subsample B}

JoCo participants were also asked about their current employment status. Those who indicated they were not currently working (i.e., unemployed, disabled, or retired and not working) were excluded from analyses of current occupational tasks. Those who indicated they were currently "Employed, either full time or part time" or "Retired, working" comprised Subsample B and were asked whether they perform each of the 9 tasks listed above at their current job. We computed the total number of tasks to which each participant reported exposure at their current job (ranging from 0 to 9), as above.

\section{Lifetime household tasks - Subsample C}

Participants were asked, "Have you ever done jobs or tasks around the house, including light and heavy housework, yard work, or home repairs for more than 1 year (from the age of 20 years and on)?". Those who responded "No" were excluded from analyses of household tasks. Those who responded "Yes" comprised Subsample C and were asked to report whether they performed 8 household tasks, which were the same as the occupational tasks listed above, except that standing was omitted. The frequency of performing each of these 8 physical tasks was rated on a 5-level scale, with participants classified as being exposed to the indicated task if they performed it often/always (vs never/seldom/sometimes). To assess the potential effect jointly contributed by these tasks, we computed the total number of household tasks to which each participant reported exposure (ranging from 0 to 8 ).

\section{Current household tasks - Subsample D}

Participants who indicated they had ever done household tasks (as described above) were asked to report the age at which they stopped doing those tasks, or if they were still performing those tasks at the time of the assessment. Individuals who indicated they were still performing these tasks comprised Subsample D. We computed the total number of household tasks each individual reported currently performing in the household (ranging from 0 to 8 ), as above.

\section{Other participant characteristics}

In addition to self-reported participant race (African American vs white), other participant characteristics included in these analyses were age (continuous variable), sex, education (some college vs no college education), and BMI (calculated as measured weight in kilograms/height in meters squared and defined continuously), depressive symptoms [assessed with the Center for Epidemiologic Studies Depression Scale (CES-D) and defined continuously ${ }^{14}$ ], self-reported prior knee injury, and KL grade of the worse knee. These variables were included because they have been associated with pain severity and/or race in previous studies $2,5,15$. 
We calculated Pearson correlations between occupation and household task counts for participants who met criteria for radiographic knee OA. Descriptive characteristics (proportions for categorical variables and medians and interquartile ranges for continuous variables) were calculated for the 4 analytic subsamples. Mean numbers of occupational and household tasks, as well as the proportions of participants reporting jobs within 6 broad US Census categories ${ }^{16}$, were calculated according to race for analytic subsamples.

We then analyzed subsamples A to D (Figure 1) in the following manner. First, we used simple linear regression to examine the associations of race with WOMAC pain scores. Second, we used simple linear regression models to examine the associations of the number of occupational or household tasks with WOMAC pain scores (regardless of race). Third, if the number of tasks was associated with significantly greater pain scores $(\mathrm{p}<0.05)$, we conducted 3 multiple linear regression models, with WOMAC pain as the outcome variable. Model 1 included race and the number of occupational or household tasks (each examined separately). This model allowed us to examine whether any racial differences in pain persisted when controlling only for the number of tasks. Model 2 included race, number of tasks, and other participant characteristics. This model allowed us to examine the change in the association between race and WOMAC pain scores when other participant characteristics were added to the model, compared with Model 1 (race and number of tasks only). This model also allowed us to examine whether occupational and household tasks were significantly associated with WOMAC pain scores when controlling for all other participant characteristics. For all linear regression models, we report unstandardized parameter estimates, which represent the amount of change in the outcome variable (WOMAC pain score) associated with a 1-unit change in the predictor variable (for example, number of tasks).

If the number of tasks explained the association of race with WOMAC pain scores (i.e., resulted in a nonsignificant association of race with WOMAC pain scores in Model 1), we further examined each of the 9 specific occupational or 8 specific household tasks, as above. We first examined whether each individual task was associated with WOMAC pain scores. For those that were significantly associated with WOMAC pain scores $(\mathrm{p}<0.05)$, we followed the steps for Models, above, with each individual task variable examined separately (in place of the number of tasks).

Because exposure to occupational and household tasks (or their associations with pain) may differ for men and women, we explored the interaction between gender and these tasks in all models of WOMAC pain. None of the interaction terms was statistically significant, so analyses were conducted for the full sample with men and women combined.

Although the residuals were not normally distributed in models of WOMAC scores, linear regression is relatively robust to this assumption. We have previously demonstrated in this same cohort that results of linear regression models of WOMAC scores produce results consistent with more complicated analytic strategies (e.g., proportional and partial proportional odds models $)^{2}$. In addition, we evaluated whether the number of occupational tasks could be adequately expressed through a linear fit in the adjusted models, comparing 
this to the fit of fractional polynomials as detailed by Royston and Altman ${ }^{17}$. Results showed that none of the tested fractional polynomials performed significantly better than the linear fit at the 0.05 level. Consequently, for purposes of parsimony and interpretability, the linear fit results are reported. All statistical analyses were performed using SAS PC, Version 9 (SAS Inc., Cary, NC, USA).

\section{RESULTS}

Among 2748 JoCo OA participants for whom data were collected between 1999 and 2004, 927 had radiographic knee OA (Figure 1). Among this group, African Americans reported greater mean numbers of physically demanding occupational tasks than whites at both the longest job (3.5, SD 2.1, vs 3.1, SD 2.4, respectively) and the current job (3.5, SD 2.0, vs 2.7, SD 2.2). African Americans were also more likely than whites to report occupations within US Census categories of Service and Operators, Fabricators, and Laborers, and they were less likely than whites to report occupations in the categories of Managerial/ Professional Specialty, and Technical, Sales, and Administrative Support (Table 1). However, African Americans reported slightly lower mean numbers of physically demanding household tasks than whites, both in terms of lifetime exposure (2.3, SD 1.6, vs 2.5 , SD 1.9) and current exposure (2.3, SD 1.6, vs 2.5, SD 1.9). The Pearson correlations between numbers of physically demanding occupational and household tasks were modest. Specifically, the correlation between current occupational and household tasks was 0.43 ( $\mathrm{p}<$ 0.001 ), and the correlation between occupational tasks at the longest job and lifetime household tasks was $0.34(\mathrm{p}<0.001)$.

From the sample of 927, we identified the 4 analytic sub-samples (not mutually exclusive) used in our analyses (Figure 1) as follows: (1) Subsample A - those who had worked outside the home for at least 1 year $(\mathrm{n}=868)$; (2) Subsample B - those who were currently working ( $\mathrm{n}=273)$; (3) Subsample $\mathrm{C}$ - those who had ever done household tasks for more than 1 year (from age 20 yrs or older, $n=811$ ); and (4) Subsample D - those who were currently performing household tasks $(n=767)$. Demographic and clinical characteristics of each subsample, as well as median numbers of self-reported physically demanding occupational and household tasks, are shown in Table 2. The subsample of participants who were currently working was younger, had a higher proportion of females, a lower mean number of depressive symptoms, and a higher proportion of individuals with some college education compared with the other 3 subsamples. The median number of occupational tasks did not differ for the longest versus current jobs, and the median number of lifetime versus current household tasks also did not differ.

\section{Occupational tasks at longest job ever held}

Among participants who indicated having ever worked outside the home or farm for pay for more than 1 year (Subsample A), unadjusted analyses showed African Americans had significantly greater WOMAC pain scores than whites $[\mathrm{b}=1.42(95 \% \mathrm{CI} 0.72,2.12)$; Table $3]$. Unadjusted analyses also showed that exposure to an increasing number of occupational tasks at the longest job ever held was associated with significantly greater WOMAC pain scores $[\mathrm{b}=0.24(95 \% \mathrm{CI} 0.08,0.40), \mathrm{p}=0.004$; data not shown in Table 3]. In adjusted 
Model 1 the association of race with WOMAC pain scores was minimally changed (reduced by only $5 \%$ ) by adjustment for the number of occupational tasks performed at the longest job ever held and remained statistically significant (Table 3). In adjusted Model 2, the association of race with WOMAC pain scores was significantly reduced (down by $88 \%$ from the unadjusted model) by additional adjustment for other patient characteristics. The number of occupational tasks was not significantly associated with WOMAC pain scores in this model.

\section{Current occupational tasks}

Among participants who indicated they were currently working outside the home or farm for pay (Subsample B), unadjusted analyses showed African Americans had significantly greater WOMAC pain scores than whites [ $b=1.61$ (95\% CI 0.42, 2.80); Table 4].

Unadjusted analyses also showed that exposure to an increasing number of occupational tasks at the current job was associated with significantly greater WOMAC pain scores $[\mathrm{b}=$ 0.39 (95\% CI 0.11, 0.67), $\mathrm{p}=0.006$; data not shown in Table 3]. In adjusted Model 1, the association of race with WOMAC pain scores was reduced by $26 \%$ by adjustment for the number of occupational tasks performed at the current job and was no longer statistically significant (Table 4). In adjusted Model 2, the magnitude of the association of race with WOMAC pain scores was reduced by $84 \%$ (compared with the unadjusted model) when additionally adjusting for other patient characteristics.

Since the number of current occupational tasks involving joint loading explained the association of race with WOMAC pain scores, specific current occupational tasks were als oexamined. The current occupational tasks significantly associated with greater WOMAC pain scores were doing heavy work while standing $[\mathrm{b}=2.70(95 \%$ CI $0.63,4.76), \mathrm{p}=$ 0.011], squatting $[\mathrm{b}=2.44$ (95\% CI 0.94, 3.94), $\mathrm{p}=0.002]$, and lifting/carrying/moving objects weighing $>10$ pounds $[\mathrm{b}=1.46(95 \% \mathrm{CI} 0.27,2.66), \mathrm{p}=0.016$; data not shown in Table 4]. In Model 1 for each of these specific task variables, the association of race with WOMAC pain scores was reduced but was still statistically significant, indicating that the individual tasks contributed partly, but not fully, to this association. In Model 2 for each of these specific task variables (which also adjusted for other participant characteristics), there was no significant association of race with WOMAC pain scores. Squatting and lifting/ carrying/moving objects weighing $>10$ pounds were significantly associated with WOMAC pain in Model 3, but doing heavy work while standing was not.

\section{Lifetime household tasks}

Among participants who reported that they had ever done jobs or tasks around the house (housework, yard work, or home repairs; Subsample C), African Americans had significantly greater WOMAC pain scores than whites $[\mathrm{b}=1.35$ (95\% CI $0.63,2.07), \mathrm{p}<$ $0.001]$. Unadjusted analyses also showed that exposure to a greater number of lifetime household tasks was associated with significantly lower WOMAC pain scores $[\mathrm{b}=-0.22$ (95\% CI $-0.42,-0.03$ ), $\mathrm{p}=0.027]$. Because the number of lifetime household tasks was not associated with greater WOMAC pain scores, multiple linear regression models were not conducted to examine whether this variable explained racial differences in pain. 


\section{Current household tasks}

Among participants who reported that they were currently doing jobs or tasks around the house (housework, yard work, or home repairs; Subsample D), African Americans had significantly greater WOMAC pain scores than whites in an unadjusted analysis $[\mathrm{b}=1.21$ $(95 \%$ CI $0.49,1.94), \mathrm{p}=0.001]$. Unadjusted analyses also showed that exposure to a greater number of current household tasks was associated with significantly lower WOMAC pain scores $[\mathrm{b}=-0.24(95 \% \mathrm{CI}-0.44,-0.04), \mathrm{p}=0.021]$. Because the number of current household tasks was not associated with greater WOMAC pain scores, multiple linear regression models were not conducted to examine whether this variable explained racial differences in pain.

\section{DISCUSSION}

In this community-based sample of adults with radiographic knee OA, as well as in other cohorts ${ }^{1,4,5}$, African Americans reported greater lower extremity pain severity than whites. This study examined whether current and lifetime exposure to occupational and household tasks contributed to these racial differences. African Americans in this rural US southern county were exposed to more physically demanding occupations than whites, in agreement with other data regarding the rural South in the same time period ${ }^{18}$. Although occupational tasks at both the longest job and the current job were significantly associated with pain in unadjusted analyses, only current job tasks substantially reduced the association of race with pain in adjusted analyses. These results suggest that among adults with knee OA who are still working, greater exposure to lower extremity joint loading is an important contributor to racial differences in pain severity. While occupational tasks performed at the longest job were not substantial contributors to racial differences in current pain severity, these results do not rule out the possibility that lifetime occupational exposures contribute to racial differences in radiographic knee OA prevalence or severity, as previously reported ${ }^{11,19}$. However, these previous, more longterm occupational exposures do not appear to be a major factor in explaining racial differences in current pain severity.

We also observed that 3 specific occupational tasks at the current job were significantly associated with greater pain severity: doing heavy work while standing, squatting, and lifting/carrying/moving objects weighing $>10$ pounds. These individual tasks did not fully explain the association of race with current pain severity, but they each reduced this association somewhat when added to regression models. These specific tasks have also been associated with increased odds for knee OA in previous studies ${ }^{20,21,22,23,24,25}$, and therefore may be important tasks to target in preventive efforts.

Among individuals with radiographic knee $\mathrm{OA}$ in this cohort, greater exposures to both lifetime and current household tasks involving lower extremity joint loading were associated with lower pain severity. One possible explanation is that individuals with lower pain levels are more likely to choose to engage in physically demanding household tasks, whereas those with greater pain cannot or choose not to perform these tasks. Unlike physically demanding occupational tasks, which some individuals may have little choice about performing, heavy household physical activity tends to be somewhat more discretionary. While these results suggest household tasks are not important correlates of current pain among individuals with 
radiographic knee OA, the literature in this area is sparse, and further work is needed to examine whether high levels of household physical demands may contribute to the risk for development of knee OA.

There are several important strengths to our study. It was conducted in a large communitybased investigation with a substantial proportion of African American participants including both men and women. Our study was novel in its approach to separately examining current compared to lifetime occupational tasks, as well as examining household tasks, which have seldom been considered in this area of research. There also are some limitations to our study. First, there are potential limitations in the accuracy of self-reported occupational hazards in general. Some previous studies have compared concordance of self-reported occupational data with objective reference measures, and results vary according to type of occupational exposures and work-related activities assessed $26,27,28,29,30,31,32,33,34,35$. Of particular relevance to our tudy, previous research has shown good agreement between selfreport and objective data regarding occupational kneeling, squatting, and standing 29,36 . Second, there is the possibility of recall or reporting bias, such that individuals with more pain may remember or report physically demanding occupational or household tasks to a greater extent than individuals without less pain, particularly if they attribute their symptoms to these tasks. Third, there is a possibility of a "healthy worker" effect, where individuals with greater pain may discontinue work and would therefore not be included in the subsample of current workers. Therefore, the associations of current occupation and knee OA pain we describe might have been based on a working population of relatively healthier patients with knee OA who were still engaged in physically demanding tasks, which would bias the associations toward the null. Fourth, occupational variables were queried with respect to participants' longest job and do not reflect total lifetime occupational exposure to these tasks. However, the average duration of the longest job in our sample was 23 years, which reflects a substantial proportion of individuals' working time. Fifth, the categories of the occupational and household variables (e.g., seldom, sometimes, often, always) depend on respondents' interpretation, which may not be consistent across all respondents. Sixth, some of the included tasks (e.g., lifting) may involve a combination of upper and lower extremity demands rather than exclusively lower extremity or knee joint loading, and all tasks likely do not contribute equally to OA symptoms. However, these occupational and household items were based on those used in previous population-based and clinic or community-based studies of occupational demands and knee and hip $\mathrm{OA}^{20,22,37}$, and they showed the expected associations with the odds of knee and hip OA in the JoCo OA cohort $^{21}$. Seventh, we examined occupational and household task exposures as categorical variables, and further investigation of specific "doses" (e.g., frequency and duration) may be important. Eighth, our study was conducted among a sample of rural participants over age 45 years, which may limit the generalizability of findings. Ninth, these analyses were crosssectional, and causality of any associations cannot be determined.

Our results support the notion that occupation-related physical activities contribute to the racial differences in knee OA outcomes. We showed that among a community-based sample of adults with radiographic knee OA, current performance of physically demanding occupational tasks was an important contributor to racial differences in pain severity. Among individuals with knee OA who continue to work, African Americans may be more 
likely to be engaged in physically demanding occupations, and discontinuing work or specific work tasks may not be an option for some. Given this limitation, it is a challenge to identify feasible options for intervention, but recent evidence suggests ergonomic and work flow changes can have a positive influence on knee pain ${ }^{38}$. Efforts to encourage better workplace policies to accommodate pain and functional limitations would have important effects $^{39}$.

\section{Acknowledgments}

Supported by cooperative agreements S043, S1734, and S3486, Centers for Disease Control and Prevention/ Association of Schools of Public Health; National Institute of Arthritis and Musculoskeletal and Skin Diseases (NIAMS) Multipurpose Arthritis and Musculoskeletal Disease Center grant 5-P60-AR30701; and NIAMS Multidisciplinary Clinical Research Center grant 5 P60 AR49465-03 and NIAMS Arthritis and Immunology Training Grant T-32-AR007416.

\section{REFERENCES}

1. Golightly YM, Dominick KL. Racial variations in self-reported osteoarthritis symptom severity among veterans. Aging (Milano). 2005; 17:264-9.

2. Allen KD, Helmick CG, Schwartz TA, DeVellis B, Renner JB, Jordan JM. Racial differences in self-reported pain and function among individuals with radiographic hip and knee osteoarthritis: The Johnston County Osteoarthritis Project. Osteoarthritis Cartilage. 2009; 17:1132-6. [PubMed: 19327733]

3. Centers for Disease Control and Prevention. Racial/ethnic differences in the prevalence and impact of doctor-diagnosed arthritis - United States, 2002. MMWR. 2005; 54:119-23. [PubMed: 15703693]

4. Groeneveld PW, Kwoh CK, Mor MK, Appelt CJ, Geng M, Gutierrez JC, et al. Racial differences in expectations of joint replacement surgery outcomes. Arthritis Rheum. 2008; 59:730-7. [PubMed: 18438917]

5. Allen KD, Oddone EZ, Coffman CJ, Keefe FJ, Lindquist JH, Bosworth HB. Racial differences in osteoarthritis pain and function: Potential explanatory factors. Osteoarthritis Cartilage. 2010; 18:160-7. [PubMed: 19825498]

6. Maetzel A, Makela M, Hawker G, Bombardier C. Osteoarthritis of the hip and knee and mechanical occupational exposure — a systematic overview of the evidence. J Rheumatol. 1997; 24:1599-607. [PubMed: 9263158]

7. Hunter DJ, March L, Sambrook PN. Knee osteoarthritis: The influence of environmental factors. Clin Exp Rheumatol. 2002; 20:93-100. [PubMed: 11892719]

8. Toivanen AT, Heliovaara M, Impivaara O, Arokoski JP, Knekt P, Lauren H, et al. Obesity, physically demanding work and traumatic knee injury are major risk factors for knee osteoarthritis - A population-based study with a follow-up of 22 years. Rheumatology. 2010; 49:308-14. [PubMed: 19946021]

9. US Bureau of Labor statistics. Labor force characteristics by race and ethnicity. US Department of Labor; 2009. 2008

10. Robinson JC. Exposure to occupational hazards among Hispanics, blacks and non-Hispanic whites in California. Am J Public Health. 1989; 79:629-30. [PubMed: 2631689]

11. Jordan JM, Helmick CG, Renner JB, Luta G, Dragomir AD, Woodard J, et al. Prevalence of knee symptoms and radiographic and symptomatic knee osteoarthritis in African Americans and Caucasians: The Johnston County Osteoarthritis Project. J Rheumatol. 2007; 31:172-80. [PubMed: 17216685]

12. Bellamy N, Buchanan WW, Goldsmith CH, Campbell J, Stitt LW. Validation study of WOMAC: A health status instrument for measuring clinically important patient relevant outcomes to antirheumatic drug therapy in patients with osteoarthritis of the hip or knee. J Rheumatol. 1988; 15:1833-40. [PubMed: 3068365] 
13. McConnell S, Kolopack P, Davis AM. The Western Ontario and McMaster Universities Osteoarthritis Index (WOMAC): A review of its utility and measurement properties. Arthritis Rheum. 2001; 45:453-61. [PubMed: 11642645]

14. Radloff LS. Th CES-D Scale: A self-report depression scale for research in the general population. Appl Psychol Meas. 1977; 1:385-401.

15. Rosemann T, Laux G, Szecsenyi J, Wensing M, Grol R. Pain and osteoarthritis in primary care: Factors associated with pain perception in a sample of 1,021 patients. Pain Medicine. 2008; 9:90310. [PubMed: 18702636]

16. US Bureau of Labor Statistics. [Internet. Accessed Oct 5, 2011] 1990 Census industrial \& occupational classification codes. Available from: http://www.bls.gov/nls/quex/r1/y97r1cbka1.pdf

17. Royston P, Altman DG. Regression using fractional polynomials of continuous covariates: Parsimonious parametric modeling. J R Stat Soc Series C (Applied Statistics). 1994; 43:429-67.

18. Swanson, LL. Racial/ethnic minorities in rural areas: Progress and stagnation, 1980-1990: Rural Economy Division, Economic Research Service. US Department of Agriculture;

19. Braga L, Renner JB, Schwartz TA, Woodard J, Helmich CG, Hochberg MC, et al. Differences in radiographic features of knee osteoarthritis in African Americans and Caucasians: The Johnston County Osteoarthritis Project. Osteoarthritis Cartilage. 2009; 17:1554-61. [PubMed: 19735758]

20. Coggon D, Croft JB, Kellingray S, Barrett D, McLaren M, Cooper C. Occupational physical activities and osteoarthritis of the knee. Arthritis Rheum. 2000; 43:1443-9. [PubMed: 10902744]

21. Allen KD, Chen JC, Callahan LF, Golightly YM, Helmick CG, Renner JB, et al. Associations of occupational tasks with knee and hip osteoarthritis: The Johnston County Osteoarthritis Project. J Rheumatol. 2010; 37:842-50. [PubMed: 20156951]

22. Cooper C, McAlindon T, Coggon D, Egger P, Dieppe P. Occupational activity and osteoarthritis of the knee. Ann Rheum Dis. 1994; 53:90-3. [PubMed: 8129467]

23. Anderson JJ, Felson DT. Factors associated with osteoarthritis of the knee in the first National Health and Nutrition Examination Survey (HANES I). Am J Epidemiol. 1988; 128:179-89. [PubMed: 3381825]

24. Felson DT, Hannan MT, Naimark A, Berkeley J, Gordon G, Wilson PW, et al. Occupational physical demands, knee bending, and knee osteoarthritis: Results from the Framingham Study. J Rheumatol. 1991; 18:1587-92. [PubMed: 1765986]

25. D’Souza JC, Werner RA, Keyserling WM, Gillespie B, Rabourn R, Ulin S, et al. Analysis of the Third National Health and Nutrition Examination Survey (NHANES III) using expert ratings of job categories. Am J Ind Med. 2008; 51:37-46. [PubMed: 18033730]

26. Smith TC, Jacobson IG, Smith B, Hooper TI, Ryan MAK, for the Millennium Cohort Study Team. The occupational role of women in the military service: Validation of occupation and prevalence of exposures in the Millennium Cohort Study. Int J Environ Health Res. 2007; 17:271-84. [PubMed: 17613091]

27. Baumgarten M, Siemiatycki J, Gibbs BW. Validity of work histories obtained by interview for epidemiologic purposes. Am J Epidemiol. 1983; 118:583-91. [PubMed: 6637985]

28. Burdorf A, Laan J. Comparison of methods for the assessment of postural load on the back. Scand J Work Environ Health. 1991; 17:425-9. [PubMed: 1838618]

29. Pope DP, Silman AJ, Cherry NM, Pritchard C, Macfarlane GJ. Validity of a self-completed questionnaire measuring the physical demands of work. Scand J Work Environ Health. 1998; 24:376-85. [PubMed: 9869309]

30. Viikari-Juntura E, Rauas S, Martikainen R, Kuosma E, Riihimaki H, Takala EP, et al. Validity of self-reported physical work load in epidemiological studies on musculoskeletal disorders. Scand J Work Environ Health. 1996; 22:251-9. [PubMed: 8881013]

31. Wiktorin C, Vingard E, Mortimer M, Pernold G, Wigaeus-Hjelm E, Kilbom A, et al. Interview versus questionnaire for assessing physical loads in the population-based MUSIC-Norrtalje Study. AmJ Ind Med. 1999; 35:441-55. [PubMed: 10212697]

32. Wiktorin C, Karlqvist L, Winkel J. Validity of self-reported exposures to work postures and manual materials handling. Stockholm MUSIC I Study Group. Scand J Work Environ Health. 1993; 19:208-14. [PubMed: 8367699] 
33. Bourbonnais R, Meyer F, Theriault G. Validity of self reported work history. Br J Ind Med. 1988; 45:29-32. [PubMed: 3342185]

34. Bond GG, Bodner KM, Sobel W, Shellenberger RJ, Flores GH. Validation of work histories obtained from interviews. Am J Epidemiol. 1988; 128:343-51. [PubMed: 3256301]

35. Stewart WF, Tonascia JA, Matanoski GM. The validity of questionnaire-reported work history in live respondents. J Occup Med. 1987; 29:795-800. [PubMed: 3681489]

36. Andrews DM, Norman RW, Wells RP, Neumann P. Comparison of self-report and observer methods for repetitive posture and load assessment. Occupational Ergonomics. 1998; 1:211-22.

37. Croft P, Cooper C, Wickham C, Coggon D. Osteoarthritis of the hip and occupational activity. Scand J Work Environ Health. 1992; 18:59-63. [PubMed: 1553513]

38. Jensen LK, Friche C. Effect of training to implement new working methods to reduce knee strain in floor layers: A two-year follow up. Occup Environ Med. 2008; 65:20-7. [PubMed: 17522136]

39. Chen JC, Linnan L, Callahan LF, Yelin EH, Renner JB, Jordan JM. Workplace policies and prevalence of knee pain and osteoarthritis: The Johnston County Osteoarthritis Project. Occup Environ Med. 2007; 64:798-805. [PubMed: 17567725] 


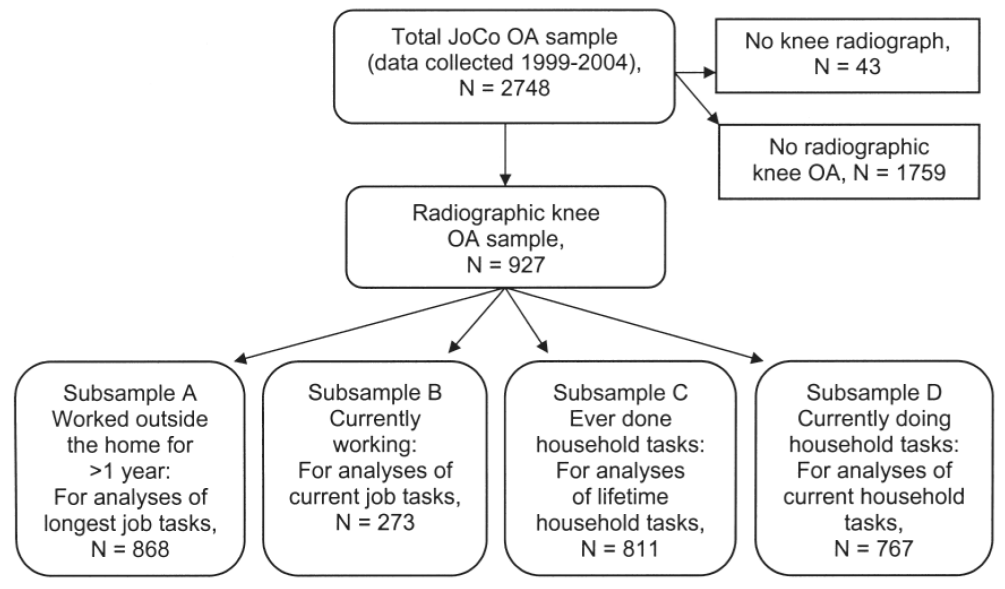

Figure 1.

Johnston County Osteoarthritis (JoCo) Project participants included in 4 analytic groups. 
Table 1

US Census industrial groups of longest and current jobs by race.

\begin{tabular}{lcccc}
\hline & \multicolumn{2}{c}{ Longest Job } & \multicolumn{2}{c}{ Current Job } \\
Occupation Group & $\begin{array}{c}\text { African } \\
\text { Americans, \% }\end{array}$ & Whites, \% & $\begin{array}{c}\text { African } \\
\text { Americans, \% }\end{array}$ & Whites, \% \\
\hline Managerial and professional specialty & 10.0 & 23.1 & 15.8 & 30.4 \\
Technical, sales, and administrative support & 11.0 & 28.7 & 11.6 & 36.0 \\
Service & 36.1 & 9.2 & 42.1 & 12.4 \\
Farming, forestry, and fishing & 3.1 & 1.5 & 3.2 & 1.9 \\
Precision production, craft and repair & 11.0 & 15.5 & 6.3 & 9.9 \\
Operators, fabricators, and laborers & 28.8 & 22.0 & 21.0 & 9.3 \\
\hline
\end{tabular}




\section{Table 2}

Characteristics of 4 analytic subsamples.

\begin{tabular}{|c|c|c|c|c|}
\hline Characteristic & $\begin{array}{l}\text { Subsample A: } \\
\text { Longest Job Ever } \\
\text { Held, } \mathbf{n}=\mathbf{8 6 8}\end{array}$ & $\begin{array}{c}\text { Subsample B: } \\
\text { Currently Working, } \\
n=273\end{array}$ & $\begin{array}{c}\text { Subsample C: } \\
\text { Lifetime Household } \\
\text { Tasks, } \mathbf{n}=\mathbf{8 1 1}\end{array}$ & $\begin{array}{l}\text { Subsample D: } \\
\text { Current Household } \\
\text { Tasks, } n=767\end{array}$ \\
\hline African American, $\%$ & 38.1 & 37.6 & 38.6 & 38.4 \\
\hline Female, $\%$ & 64.5 & 56.4 & 65.0 & 65.8 \\
\hline Median age (IQR), yrs & $66.5(58.5,76.1)$ & $59.1(54.7,67.0)$ & $66.1(58.1,75.2)$ & $66.1(58.2,74.9)$ \\
\hline Some college education, $\%$ & 23.7 & 31.0 & 23.4 & 23.8 \\
\hline Median BMI (IQR) & $31.4(27.4,37.1)$ & $32.0(28.7,36.9)$ & $31.5(27.6,37.1)$ & $31.5(24.4,37.1)$ \\
\hline Median depressive symptoms (IQR) & $4.0(1.0,9.0)$ & $2.0(0.0,6.0)$ & $4.0(1.0,9.0)$ & $3.0(1.0,9.0)$ \\
\hline Knee injury, \% & 15.1 & 18.4 & 15.3 & 15.0 \\
\hline Median K-L grade of worse knee & $3.0(2.0,3.0)$ & $3.0(2.0,3.0)$ & $3.0(2.0,3.0)$ & $3.0(2.0,3.0)$ \\
\hline Median WOMAC pain score (IQR) & $5.0(1.0,10.0)$ & $4.0(0.0,8.0)$ & $5.0(1.0,10.0)$ & $5.0(1.0,9.0)$ \\
\hline Median no. occupational tasks (IQR) ${ }^{\dagger}$ & $3.0(1.0,5.0)$ & $3.0(1.0,4.0)$ & - & - \\
\hline Median no. household tasks (IQR) $)^{\dagger \dagger}$ & - & - & $2.0(1.0,3.0)$ & $2.0(1.0,3.0)$ \\
\hline
\end{tabular}


Table 3

Unadjusted and adjusted linear regression models of WOMAC pain among participants with knee osteoarthritis who worked outside the home > 1 year (Subsample A).

\begin{tabular}{|c|c|c|c|}
\hline Feature & $\begin{array}{c}\text { Unadjusted model } \\
\mathbf{b}^{*}(95 \% \mathrm{CI})\end{array}$ & $\begin{array}{l}\text { Adjusted Model } 1 \\
\text { b (95\% CI) }\end{array}$ & $\begin{array}{l}\text { Adjusted Model } 2 \\
\text { b (95\% CI) }\end{array}$ \\
\hline African American race (vs white) & $1.42(0.72,2.12)^{\dagger}$ & $1.35(0.60,2.09)^{\dagger}$ & $0.17(-0.53,0.88)$ \\
\hline No. occupational tasks at longest job & - & $0.21(0.05,0.37)$ & $0.13(-0.02,0.29)$ \\
\hline Age & - & - & $0.00(-0.03,0.04)$ \\
\hline Some college (vs no college) & - & - & $-0.74(-1.53,0.05)$ \\
\hline Female & - & - & $1.55(0.81,2.28)^{\dagger}$ \\
\hline BMI & - & - & $0.11(0.06,0.16)^{\dagger}$ \\
\hline Depressive symptoms & - & - & $0.17(0.12,0.21)^{\dagger}$ \\
\hline Knee injury (vs no knee injury) & - & - & $1.13(0.19,2.07)^{\dagger}$ \\
\hline K-L grade of worse knee & - & - & $1.08(0.63,1.53)^{\dagger}$ \\
\hline Model R ${ }^{2}$ & 0.019 & 0.027 & 0.229 \\
\hline
\end{tabular}




\section{Table 4}

Unadjusted and adjusted linear regression models of WOMAC pain among participants with knee osteoarthritis and currently working (Subsample B).

\begin{tabular}{lccc}
\hline Feature & $\begin{array}{c}\text { Unadjusted Model } \\
\mathbf{b}^{*}(\mathbf{9 5 \%} \mathbf{C I})\end{array}$ & $\begin{array}{c}\text { Adjusted Model 1 } \\
\mathbf{b}(\mathbf{9 5 \%} \mathbf{C I})\end{array}$ & $\begin{array}{c}\text { Adjusted Model 2 } \\
\mathbf{b}(\mathbf{9 5 \%} \mathbf{C I})\end{array}$ \\
\hline African American race (vs white) & $1.61(0.42,2.80)^{\dagger}$ & $1.19(-0.08,2.45)$ & $0.26(-0.99,1.50)$ \\
No. current occupational tasks & - & $0.35(0.07,0.63)^{\dagger}$ & $0.31(0.04,0.59)^{\dagger}$ \\
Age & - & - & $0.03(-0.05,0.10)$ \\
Some college (vs no college) & - & - & $-0.22(-1.51,1.07)$ \\
Female & - & - & $2.14(0.94,3.34)^{\dagger}$ \\
BMI & - & - & $0.01(-0.08,0.10)$ \\
Depressive symptoms & - & - & $0.20(0.11,0.29)$ \\
Knee injury (vs no knee injury) & - & - & $1.59(0.02,3.17)^{\dagger}$ \\
K-L grade of worse knee & -0.045 & $1.05(0.17,1.93)$ \\
Model R ${ }^{2}$ & - & - & 0.233 \\
\hline
\end{tabular}

* Unstandardized parameter estimate.

${ }^{\dagger} \mathrm{p}<0.05$. BMI: body mass index; K-L: Kellgren-Lawrence; WOMAC: Western Ontario and McMaster Universities Osteoarthritis Index. 